\title{
A poesia e o Ensino de línguas
}

\author{
Newton Freire Murce Filho*
}

\section{RESUMO}

Este texto tem como objetivo discutir o papel da poesia no processo de ensino de línguas. Argumenta-se que é necessário aprender a apreciar o que a poesia faz com a língua e com o corpo por meio da produção do novo.

PalaVras-chave: corpo, língua, poesia.

\section{Poetry and the teaching of languages}

\section{Abstract}

This text aims at discussing the role of poetry in the process of teaching languages. It is argued that it is necessary to learn how to appreciate what poetry does to language as well as to the body by means of the production of something new.

KEY worDs: body, language, poetry.

Há um cio vegetal na voz do artista.

/.../

Palavra de artista tem que escorrer substantivo escuro dele.

Tem que chegar enferma de suas dores, de seus

limites, de suas derrotas.

Ele terá que envesgar seu idioma ao ponto de enxergar no olho de uma garça os perfumes do

sol.

Manoel de Barros

\section{INTRODUÇÃO}

Em um trabalho anterior, abordei, brevemente, a questão da poesia, dizendo que

\footnotetext{
* Professor do Cepae/UFG, doutorando em Lingüística na Unicamp, ator. E-mail: murcef@uol.com.br
} 
80 Revista Solta a Voz, v. 16, n. 1

o poético, por se sustentar no jogo de significantes, traz, por isso mesmo, a possibilidade do novo, de rupturas, de surpresas, de criação de chistes e de exploração dos sons de uma língua no que esta, em sua ordem - e (diz!)ordem -, autoriza e desautoriza em termos de jogos metafóricos e metonímicos. Por se produzir no jogo de sons e diferenças, o poético permite que se suspenda o nível do sentido para se trabalhar no nível do significante que, por não constituir um sentido pré-estabelecido, afeta o sujeito em sua materialidade sonora, singularmente, no modo como ele ressoa no corpo. (Murce Filho, 2003, p. 72)

Retomo o tema neste texto, a partir do que sugeri sobre como a poesia pode afetar o corpo, ressoando nele e convocando-o. Quero pensar isso e o ensino de línguas. Por que falar do corpo? Porque acredito que é somente pela via do corpo e no corpo que algo do novo pode afetar o sujeito, convocá-lo, mobilizando-o.

É preciso esclarecer, antes de mais nada, o entendimento que temos de que a poesia não desempenha um mero papel de comunicação, lembrando que a finalidade do texto poético consiste em si mesmo, na mensagem por ela própria, nos termos de Jakobson (1999, p. 128), e é disso que se trata quando ele fala da função poética. Para esse lingüista, toda mensagem voltada para si própria traz a ambigüidade como característica intrínseca, e a mensagem de duplo sentido torna também seu destinatário cindido, bem como seu remetente e mesmo a referência torna-se cindida (Jakobson, 1999, p. 150).

Sobre o fato de a poesia estar além da mera comunicação, vale trazer Valéry (1957, p. 1330), que, ao contrapor a comparação da prosa com o caminhar e da poesia com a dança, afirma: "o caminhar, como a prosa, visa a um objeto preciso. Ele é um ato dirigido para algo que queremos atingir. [...] A dança é totalmente diferente [...]. Ela não se dirige a parte alguma". A poesia, encerrando-se em si mesma, pode fazer pensar em uma suposta "inutilidade", uma inexistência de efeitos "práticos", se comparada a textos informativos, por exemplo. Para Perrone-Moisés (2000), porém, é justamente por sua "inutilidade" que a poesia põe em questão a utilidade dos outros textos e da própria linguagem, pois ela - a poesia -

vem lembrar, imperiosamente, que tudo é linguagem, e que esta engana. A linguagem está o tempo todo fingindo-se de transparente, de prática e 
Revista Solta a Voz, v. 16, n. 181

de unívoca, e nos enreda num comércio que nada tem de essencialmente verdadeiro e necessário. (Perrone-Moisés, 2000, p. 32)

Tendo esse esclarecimento em vista, é importante observar desde já, então, que o papel do professor, de acordo com o que vamos desenvolver aqui sobre a poesia, diz respeito menos ao pretexto "utilitário" de ensinar uma língua por meio do texto poético, do que a (re)aprender, junto com o aluno, a apreciar aquilo que um poema faz com a língua a partir dos seus dois modos básicos de arranjo, isto é, a seleção e a combinação ou a metáfora e a metonímia. Trata-se de apreciar o que a própria língua permite e proíbe, regula e faz surpreender, mantém e transgride, oferecendo como efeito a produção do novo. É esse novo que ressoa no corpo do leitor, fazendo sentido para ele ainda que não se compreenda esse sentido -, arrebatando-o e, quem sabe, modificando-o de alguma forma. É esse novo, pela escrita, que nos introduz num mundo diferente do nosso, esse novo que a poesia faz comparecer porque ela "é a criação de um sujeito assumindo uma nova relação simbólica com o mundo" (Lacan, 1988, p. 94).

Para Didier-Weill (1999, p. 11), ao falar do músico e do poeta, o novo é produzido porque a poesia extrai o significante do código léxico para alçá-lo ao ponto de onde o não-sentido, próprio da música, dá a ouvir o que tem de inaudito. Assim, "o músico ou o poeta é aquele que pode fazer ouvir uma nota com o poder de fazer soar o inaudito, arrancando-o ao real de onde fora expulso". Se lhe somos tão reconhecidos, "é porque ele nos permite descobrir que em nós reside o recurso de reencontrar a existência do inaudito no instante em que o constituímos como tal, expulsando-o" (Didier-Weill, 1999, p. 148-149). Conforme observa o autor, é justamente porque o inaudito como tal exige ser ouvido, ser arrancado à prisão em que o mantém o supereu, que os poetas sempre foram mais ou menos inspirados pela metáfora da prisão de que lhes era necessário escapar.

Quando digo aprender a apreciar o que a poesia faz com a língua, evidentemente a questão do sentido vem à tona. Mas antes de abordá-la, vale citar um trecho de Mannoni (1992, p. 42) ao tratar do tema:

O fato de que a obra literária culmina na constituição de um objeto (um texto), de que ela é mediadora entre as pessoas à maneira de uma coisa que se permuta, "mercadoria mental", e não como uma fala endereçada; de que 
82 Revista Solta a Voz, v. 16, n. 1

conserva uma certa independência em face do uso íntimo que aquele que a recebe pode fazer dela; de que esse uso situa-se na relação imaginária, tal como é na relação imaginária que o escritor escreve, todas essas considerações não impedem que o texto tenha seu sentido intrínseco. Ou seus sentidos.

O interessante, contudo, segundo ele, é que a melhor maneira de ler um poema é por meio de uma "atitude inocente", que consistiria em quê? Em o leitor desprender-se justamente de um sentido préestabelecido por um crítico ou por uma suposta interpretação única, correta, e deixar-se ser atingido, arrebatado pelo que se lê nas palavras, ou seja, "o que eu, leitor, quero elucidar, se sou sincero, é o modo como sou arrebatado e discutido". Nesse sentido, o comentário, de um crítico ou de quem quer que seja, incluindo, portanto, o professor, adquire um valor de resistência, e seria também uma defesa "tentar ligar o sentido do poema, aquilo que me arrebatou, ao que o poeta deve ter realmente sentido" ao escrever, pois, embora se possam fazer suposições bastante coerentes, isso pouco importa diante do essencial que é "o modo como o sentido me atinge" (Mannoni, 1992, p. 43).

$\mathrm{O}$ autor acrescenta ainda que a ambigüidade de um texto literário, muitas vezes assimilada à própria dimensão poética do texto, existe tanto para o autor quanto para o leitor, uma vez que "não há um sentido atribuível só ao autor, pela única razão de que é um sentido, ou seja, algo que um outro, justamente, devia atribuir" (Mannoni, 1992, p. 44 - grifo do autor). Para ele, o que é imputável é o lado puramente subjetivo, que, como tal, não tem sentido. Afinal, autor e leitor, cada um possui suas próprias resistências e opacidades, ninguém sendo possuidor do sentido: “o poeta, perante sua própria obra, só pode converter-se em seu leitor, mais ou menos clarividente, mais ou menos perplexo" (Mannoni, 1992, p. 45).

O autor observa também que é ilusão pensar que o poeta poderia fazer passar o sentido do inconsciente para o consciente, participando-nos suas descobertas, pois "o discurso poético não nos dá a impressão de exprimir o que é secreto, mas de respeitá-lo como inexpresso, de lhe assinalar o lugar mas contornando-o" (Mannoni, 1992, p. 4546). O psicanalista conclui seu texto perguntando se não seria justamente o fato de servir-se da linguagem, não para assumir o inconsciente, mas para "contorná-lo", o aspecto essencial da atitude poética. Nesse caso, a poesia seria então o desconhecimento levado a um ponto de 
Revista Solta a Voz, v. 16, n. 183

inocência suficiente para que a verdade mais profunda, impossível de comunicar pela palavra que alguém existente endereça a alguém existente, pudesse emergir de uma linguagem alienada, sem ser imputável a ninguém (Mannoni, 1992, p. 47).

Essa questão de "contornar" o inconsciente nos interessa porque nos remete à Coisa (das Ding), isto é, a isso que constitui qualquer produção artística, o contornar, o bordejar o vazio, o irrepresentável, a Coisa, enfim, e que desempenha papel importante na produção do novo.

Para entendermos um pouco o papel da Coisa na produção do novo na poesia, é preciso retomar Freud (1969a, 1977), ao conceber o aparelho psíquico, que é o aparelho de linguagem. É no texto sobre as afasias que ele (Freud, 1977) propõe o que chama de um campo complexo de associações que nomeia como aparelho de linguagem, definido como uma estrutura, efeito da relação dinâmica entre os campos acústico, visual e motor. No apêndice $\mathrm{C}$ do texto $O$ inconsciente, Freud (1969a, p. 217) define a palavra como uma "apresentação (ou representação) complexa, que vem a ser uma combinação de elementos auditivos, visuais e cinestésicos (ou motores)". A articulação da significação é trazida pela ligação do complexo "fechado" da representaçãopalavra com o complexo "aberto" da representação-objeto, por meio, principalmente, da imagem acústica da palavra e da imagem visual do objeto. A representação-palavra está ligada às representações-objeto pela imagem acústica.

Uma vez que a representação é um processo associativo, ela deve ser entendida como a diferença entre as duas séries de associações: de representação-palavra e de representação-objeto. A palavra corresponde a uma associação de imagens mnêmicas, e seu significado sobrevém da articulação da imagem acústica com as associações de objeto.

Uma representação, contudo, não é a reprodução de um objeto externo, isto é, seu significado não provém do objeto, mas das associações entre as várias representações. Essas associações se fazem nos dois sentidos: a palavra adquire significação pela ligação com a representação-objeto, e o objeto ganha identidade pela articulação com a representação-palavra. Não há, portanto, significação anterior ao pensamento; ela se dá pela diferença nos vários registros através dos quais se articulam as associações ou representações. E o processo associativo não consiste apenas em associar (primariamente) elementos acústicos, visuais e motores, como é o caso das associações dos elementos da represen- 


\section{Revista Solta a Voz, v. 16, n. 1}

tação-palavra, mas também em associá-la com outras representaçõespalavra. Para Freud, então, representação e objeto são independentes, e a linguagem não é feita para designar as coisas.

A noção de que a significação não se dá antes da articulação da palavra com as associações de objeto permite dizer que, para Freud, não há pensamento anterior à linguagem. No entanto, embora não haja pensamento anterior à linguagem, há o aquém, o anterior ou o além da linguagem, algo fora do aparelho da linguagem e é aí que algo da ordem da Coisa insiste. Trata-se do vazio, do impossível, do irrepresentável que persiste. É nessa "região" que a arte é predominantemente produzida, que a poesia é produzida. É esse vazio, isso que é da Coisa, que a arte bordeja, contorna, possibilitando a criação do novo.

Conforme esclarece Moraes (1999), a Coisa é uma estrutura constante, percepção que cria o estado de desejo. Ela não se reduz a um componente perceptivo qualquer; é algo que estará atuando fora daquilo que é o aparelho psíquico (ou de linguagem), fora do que é regulado pelo princípio do prazer, percepção sem resíduo, sem representação. Espaço deixado por Freud para o vazio objeto da satisfação, para o impossível da satisfação. Para Lacan (1997), das Ding é o Outro absoluto do sujeito, que se trata de reencontrar, porém só o reencontramos no máximo como saudade; a Coisa é o que se apresenta, e se isola, estranho em torno do qual gira todo o movimento da Vorstellung (representação).

Conforme se observa em Freud (1969b), relido por Moraes (1999), aquilo que o Eu-prazer não compreende, através do próprio corpo, na experiência com o semelhante, é a Coisa, parte inassimilável do Eu e projetada como não-Eu no interior do Eu, algo que não vai ser representado e que se situa aquém da imagem verbal, um fora da possibilidade da simbolização, mas ao mesmo tempo algo que está muito próximo do sujeito, porque é expulso do seu interior, assim representando-o como dividido: "o psiquismo inconsciente se organiza no ato fundamental do afastamento da Coisa, que presentifica, nessa relação primitiva do dentro e do fora, o outro do Eu" (Moraes, 1999, p. 70). A poesia pode convocar isso que é da Coisa justamente porque convoca o corpo, tanto o de quem escreve quanto o de quem lê, para aquilo que é estranho e ao mesmo tempo familiar, ou seja, o novo que se produz a partir do que já está aí, isto é, a língua mesma como lei, mas lei que é transgredida nela e por ela mesma nas mãos do poeta. 
Revista Solta a Voz, v. 16, n. 185

Ainda a partir de Freud (1969a) em O inconsciente, Moraes (1999, p. 123) observa que

o registro do inconsciente é precedido por uma série de extratos de memória que permanecem como "sobrevivências", que não foram reescritos e que se constituem de inscrições de gozo que precedem, necessariamente no tempo e na estrutura, a formação do inconsciente. Esses conteúdos recalcados são regidos pelas leis vigentes no momento da "não-tradução" e constituem núcleos cristalizados que podem atrair outras representações, antes que intervenha qualquer intenção consciente.

Acredito que esses núcleos cristalizados constituem a matériaprima do poeta, a Coisa da palavra, os traços visuais e auditivos, o recalcado suspenso. Muito da produção do novo em poesia advém da parte do campo complexo de associação (o aparelho de linguagem) que faz ligação com o complexo associativo aberto que compõe as representações-objeto, ou representações-coisa, ou seja, complexo associativo de representações acústicas, táteis e visuais. Trata-se, enfim, do trabalho do poeta com o que a palavra tem de Coisa, trabalho com o corpo da expressão, o corpo verbal, nas palavras de Derrida (1995).

Conforme observa Moraes (1999, p. 70),

ao se afastar, a Coisa marca a presença do vazio e, ao mesmo tempo, a impossibilidade de se encontrar novamente o que teria sido uma vez percebido. Recolhe-se à forma representacional específica que Freud nomeia de representação-coisa, preservando, assim, o nível mais primário/ real, mais material/verdadeiro da representação.

É nesse nível que o poeta trabalha, buscando o primário, o material, o som, o ritmo, a verdade. Isso tem relação com a maneira como o sonho se forma, uma vez que nele as palavras são tratadas como coisas, perdendo seu significado no código e revestindo-se de um outro sentido, o sentido do desejo. O sonho escolhe palavras capazes de serem, para além de sua significação, signos de um gozo, de uma vertigem, propiciada por essa operação de escrever com um escrito na homofonia. Nessa operação, o sentido não conta (Moraes, 1999). Assim,

as leis da linguagem (condensação e deslocamento) vigoram na palavra, submetendo-a à função de uma encruzilhada (das coordenadas fundamen- 
86 Revista Solta a Voz, v. 16, n. 1

tais do aparelho: sincronia e diacronia), cujo efeito de multiplicidade de significações se encontra à mercê da lei do desejo. Se as palavras estão predestinadas à ambigüidade [...], é porque o desejo usa a palavra para escrevê-la seguindo outros modos de associação. (Moraes, 1999, p. 117-118)

O trabalho do poeta é feito diretamente sobre a letra, que é o que barra o significante de todo significado preestabelecido. A letra está, por um lado, vinculada ao significante pela sua estrutura fonemática, por outro, está distinta do significante, quando dele pode se desgarrar, cumprindo uma função diferente da função de representação, isto é, para além da dimensão simbólica, a função de operadora da cifração, propiciando novos efeitos, que não concernem apenas a novos sentidos, através do som, mas a um saber sobre o gozo, pela escrita (Moraes, 1999).

Antes de terminar, reproduzo mais um trecho de Moraes (1999, p. 134), a respeito de Lacan, porque nele podemos notar a ligação entre o trabalho com a letra, que é o que faz o poeta, e a produção de gozo na linguagem. A pesquisadora afirma que interessa a Lacan,

nos modos de desgarramento da letra em relação ao sistema simbólico, o fato de essa ruptura estar associada a uma produção de gozo, entendendo-se aí o gozo no dizer, feito do próprio tecido da linguagem, onde o desejo encontra suas regras. A textura da linguagem permite, no jogo do gozo, o retorno do objeto desejado. O gozo é o trabalho do inconsciente. O prazer é do pré-consciente ou do consciente. O gozo é da ordem do inconsciente e se apresenta como mescla de embriaguez, vertigem, ruptura e estranheza, momento em que se transpõem limites. No gozo há ausência de significante representativo, o inconsciente goza sem sujeito. Algo goza em nós. O gozo é algo da ordem da convocação da linguagem, tendo em vista que implica o sujeito no discurso, mas só na medida em que o discurso o ultrapassa. Como não é simbolizado, nem simbolizável, ele é real. É o vazio central, inteiramente exterior da Coisa (das Ding), em torno da qual todas as representações se organizam [...]. Nos jogos de concatenação da cadeia significante, o jogo do gozo se apresenta pelo fato de nosso desejo estar constituído de nossas relações com as palavras. É quando a linguagem é utilizada no seu próprio tecido (naquilo que chamamos de letra), que o gozo pode fazer seu jogo.

Finalizo aqui, retomando o início do texto em que apontei a importância da poesia ressoando no corpo do leitor pela via de uma 
materialidade sonora, visual, plástica que, selecionada e combinada de uma dada maneira pelo poeta, toca, arrebata o sujeito de maneira singular, por meio do inesperado rompendo o esperado, do estranhamento provocando vertigem, fazendo sentido, ainda que não se saiba de que sentido se trata ou por que se faz sentido. De qualquer modo, o poético toca o corpo e isso não é sem conseqüências. Professor e aluno, sabendo disso, devem, na sua relação com o poético, implicar-se como sujeitos, deixando o corpo ser tomado pela letra.

\section{REFERÊNCIAS}

DERRIDA, J. A escritura e a diferença. São Paulo: Perspectiva, 1995.

DIDIER-WEILL, A. Invocações: Dionísio, Moisés, São Paulo e Freud. Rio de Janeiro: Companhia de Freud, 1999.

FREUD, S. O inconsciente. Rio de Janeiro: Imago, 1969a. (ESB, v. 14). v. 14).

Pulsões e destinos das pulsões. Rio de Janeiro: Imago, 1969b. (ESB,

- A interpretação das afasias. Trad. (do italiano) de Antônio P. Ribeiro. Lisboa: Edições 70, 1977.

JAKOBSON, R. Lingüística e comunicação. São Paulo: Cultrix, 1999.

LACAN, J. As psicoses: Seminário livro III. Rio de Janeiro: Jorge Zahar, 1988.

- A ética da psicanálise: Seminário livro VII. Rio de Janeiro: Jorge Zahar, 1997.

MANNONI, O. Um espanto tão intenso. Rio de Janeiro: Campus, 1992.

MORAES, M.R.S. Materna/estrangeira: o que Freud fez da língua. 1999. Tese (Doutorado em Lingüística) - Instituto de Estudos da Linguagem, Universidade Estadual de Campinas, SP, 1999.

MURCE FILHO, N. F. Da escritura ao corpo e do corpo à escritura. Revista Solta a Voz, Goiânia, v. 14, n.2, p. 67-74, jul.-dez., 2003.

PERRONE-MOISÉS, L. Inútil poesia e outros ensaios breves. São Paulo: Companhia das Letras, 2000. 
88 Revista Solta a Voz, v. 16, n. 1

VALÉRY, P. Oevres. Tomo I. Paris: Gallimar (Bibliothèque de la Pléiade), 1957.

Recebido em: 15 fev. 2005

Aceito em: 12 abr. 2005 